\title{
Computer-aided Tools for Identifying Organisms and their Importance for Protected Areas
}

\author{
Pier Luigi Nimis \& Stefano Martellos
}

Keywords: biodiversity, context-awareness, Dryades, education, KeyToNature, internet

\section{Abstract}

This paper focuses on computer-aided tools for identifying organisms and on relevant implications for rethinking environmental education in protected areas. The new tools have several advantages over traditional paper-printed keys: 1) being disentangled from systematics, they can be made much easier and also be used by non-experts, 2) they give access to a large number of images, hyperlinks and metadata, 3) they run on several media, including PDAs and smartphones, which permit their use directly in the field, 4) they can be modified and personalized by the user. We give examples of their introduction in protected areas as a powerful tool for enhancing the knowledge of the local biodiversity and for developing projects of environmental education.

\section{Introduction}

Nature protection, research and environmental education are among the main aims of parks and nature reserves. These aims are closely related: the knowledge and understanding of biodiversity is fundamental for its protection. Several protected areas across Europe have invested important resources for basic research on their biodiversity, which have resulted in detailed checklists of at least some major groups of organisms (usually vascular plants and vertebrates, but also lichens, fungi, etc.). However, there is a huge gap between the results of scientific research and the real knowledge of biodiversity by those who visit a protected area: the checklists usually appear as a rosary of odd Latin names to a layperson. How many visitors of a park can appreciate its biodiversity during an excursion? How many are able to identify a plant, an animal or a fungus which has attracted their attention? Until recently, identification was considered as a job for specialists. Hence, parks and nature reserves usually explain "their" biodiversity with a few general statements on its richness, plus some pictorial descriptions of a few "prominent" species, shown on booklets, posters or online.

This paper focuses on a new approach for teaching and learning biodiversity, which is now possible, thanks to the development of computer-aided tools for identifying organisms that are much more user-friendly than the traditional paper-printed keys, booklets and posters. We shall concentrate on the experience gained within the European project KeyToNature in introducing the new identification tools in formal education across Europe, focusing on relevant aspects for rethinking environmental education in protected areas.

\section{Identification tools: from paper-printed books to the internet}

In the past, the main tools for identifying organisms were printed on paper, usually as dichotomous keys. The constraints of a paper-printed text were forcing

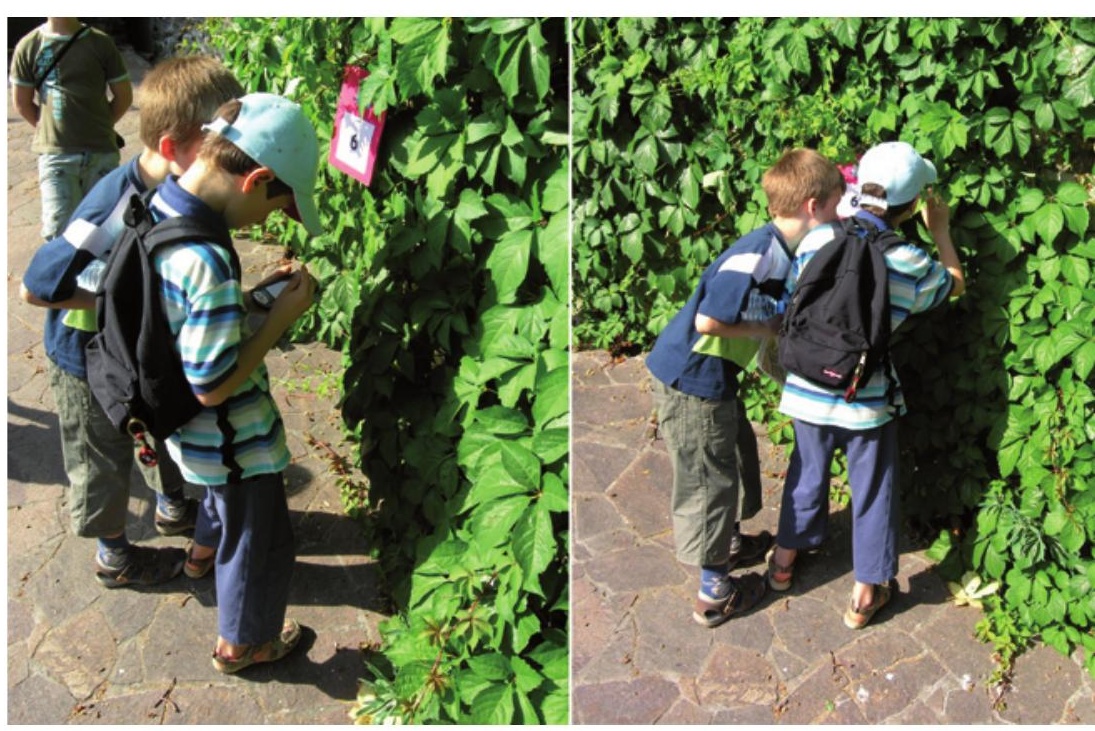

Children involved in an identification game at the Botanical Garden of the Trieste University, using PDAs

most authors to organize information according to the hierarchical scheme of biological classification, to the point that the terms "classification" and "identification" are often confused by laypeople. However, classification and identification - albeit related - belong to two different operational processes (Bridgman 1927). Classification is the job of taxonomists, while identification can be fun for anybody. The great American lichenologist Mason Hale was aware of this fact when he produced his classical "booklet" How to know the lichens (Hale 1969, 1979), where the basic structure of the dichotomous keys is completely disentangled from systematics. Classical keys first lead to families, then to genera, and finally - if everything works out - to species. Supraspecific taxa, however, are mostly characterized by "difficult" features - difficult to observe and appreciate by laypeople - which makes these keys intrinsically "difficult". Many of the easy-to-lookat features, such as the colour of flowers, and those referring to ecology and distribution, are alien to the hierarchical-taxonomic scheme followed in classical keys and thus are usually downscored. 


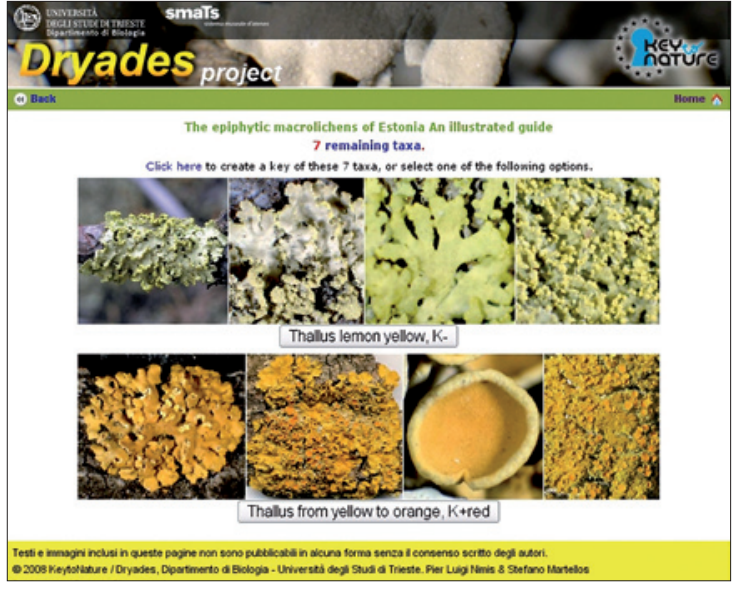

Figure 1 - A passage of the dichotomous query interface (a key to lichens): every character and character state is richly illustrated

Today, computer-based programs can easily organize a wealth of morphological-anatomical data, plus the distributional-ecological information usually hidden in the ocean of scientific literature, to generate identification tools which can be rendered much more userfriendly and easier than the classical paper-printed keys. Traditional paper-printed keys have several drawbacks: - Being printed on paper, their content is "frozen". Nomenclatural-taxonomic changes, progress in exploration, the discovery of new species, often render a key outdated within a few years. Computer-aided keys, however, can be updated and corrected in real time.

The larger the number of taxa, the more difficult it is for the user to identify an organism. Several "classical" paper-printed keys (e.g. a national flora) refer to large areas, including a high number of species with widely different distribution and ecology: they often ask for the observation of "difficult" characteristics to distinguish between species which will be never found growing together (e.g. a Trifolium endemic in the Alps and one restricted to the warmest and driest part of the Mediterranean). Computer-aided tools permit an easy reduction of the set of organisms using different combinations of morphological, ecological, distributional data (e.g. "freshwater fish of park X", "lichens growing on bark in the E Alps", "woody plants found near our Visitor Centre", etc.).

The old paper-printed keys are "rigid": they contain a huge amount of information which is frozen into the format and the logical structure chosen by the author. Computer-aided keys are much more "elastic", and can generate outputs which in the past would have required a huge amount of work. So it is now possible to extract from a nationwide key: a) regional-local keys (e.g. of a biotope, a nature park, a province);

b) keys for "virtual habitats", by combining distributional data with ecological indicator values (see Nimis \& Martellos 2001),

c) keys for special users, such as schoolchildren.



Figure 2 - An example of multi-entry query interface (for vascularplants): the user can specify several characters in a single step

Furthermore, the new computer-aided identification tools can be consulted on different media, with widely different usability features: they can be stored on CD or DVD-ROMs, can run on mobile devices such as PDAs (Personal Digital Assistants) and smartphones, and can be accessible on the web (Stevenson et al. 2003; Brach \& Song 2005, 2006; Agarwal et al. 2006; Farr 2006; Martellos \& Nimis 2008).

The first approaches to interactive identification were simple paper-printed dichotomous keys, converted into HTML pages, sometimes with links between the dichotomies, plus notes and images. These approaches required a pre-existing key and were not particularly original. Much more important are systems that are able to generate ex-novo original identification tools. One of them is Intkey (Dallwitz, 1980; Dallwitz et al. 1993, 1995, 2000), based on DELTA (Description Language for Taxonomy, Dallwitz 1980; Dallwitz et al. 2002), developed since 1971 by the Division of Entomology of CSIRO (Australia). Other systems have been developed by different research centres; some of them commercial, such as Lucid (http://wwwlucidcentral.org/), others are available for free for scientific purposes only, such as Linnaeus II (http://www.eti. uva.nl/), or in general, such as Meka (http://ucjeps. berkeley.edu/meacham/meka/). All of these tools greatly reduce the effort needed to produce identification tools, since they permit authors to easily modify or add new data.

The new tools allow approaching the identification of an organism via different query interfaces. The bestknown are:

1) dichotomous query interface, which drives the user in the choice between two states of a feature (Figure 1), 2) multi-entry query interface, which allows the use of several features together, sharply reducing the number of taxa in a single step (Figure 2),

3) multi-access query interface, in which the user can freely choose among several features. 


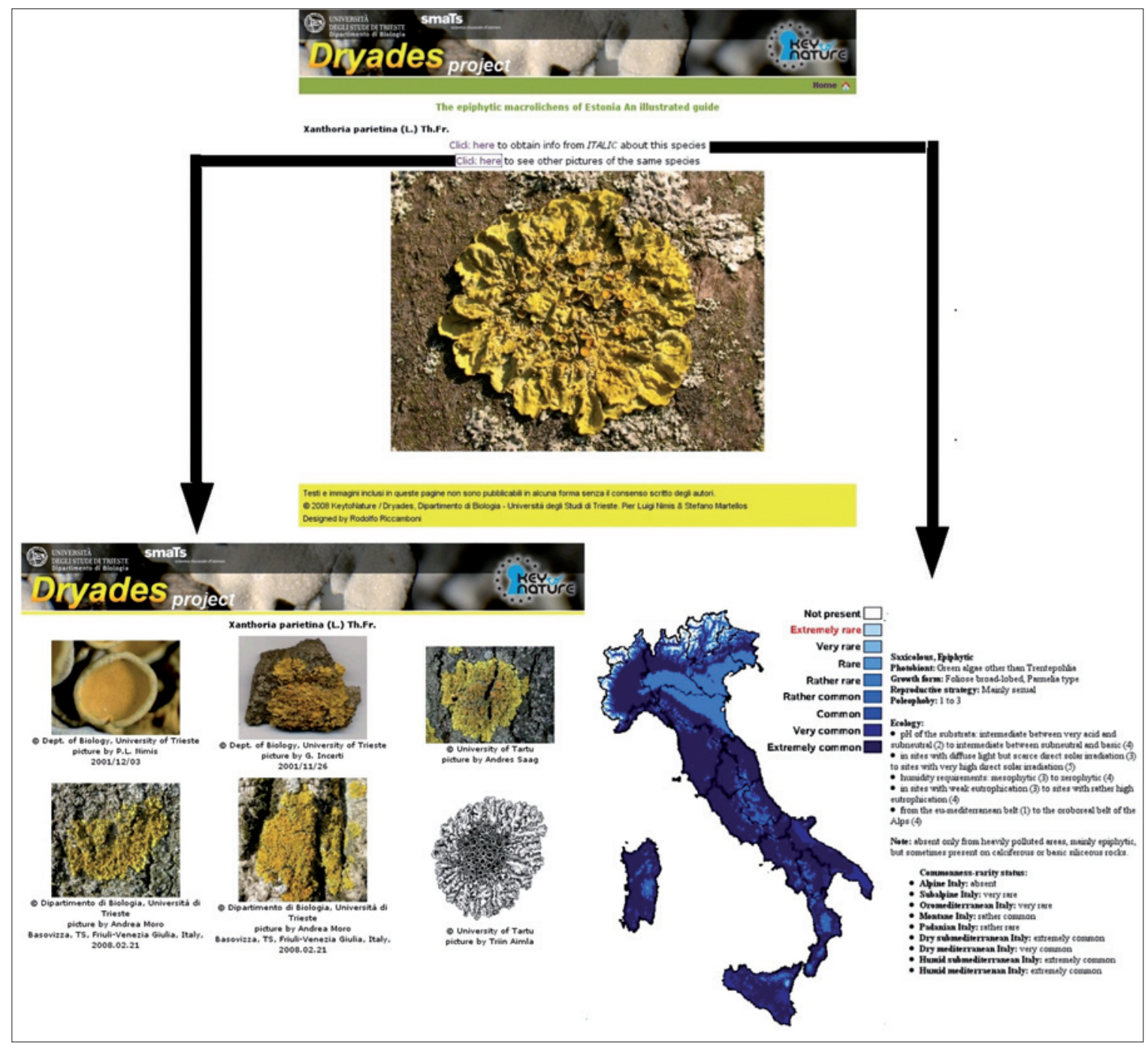

Figure 3 - At the end of the identification path, the computer gives access to a taxon page with images, notes, distribution maps and links to other resources (the example refers to the lichen Xanthoria parietina)

At the end of the identification process, computeraided keys usually display rich taxon pages (Figure 3), with a potentially unlimited amount of data and links to different resources (nomenclatural, distributional and ecological data, local uses, links to other databases, images etc.). At any stage of the identification process the user can obtain a printable, illustrated version of the key (Figure 4).

Compared to the traditional, paper-printed and manually-mentally generated keys, digital interactive keys have an enormous potential for environmental education: not only they can be more user-friendly and easier, but also portable, and hence much more usable in the field.

\section{KeyToNature / Dryades}

The new possibilities for developing user-friendly, interactive identification tools led the European Commission to finance a large project - KeyToNature - devoted to the introduction of such tools in the world of formal education. KeyToNature (www.keytonature. eu) is a three-year project, started in 2007, funded un- der the eContentplus programme. The project aims at achieving a common European approach in teaching biodiversity, mainly focusing on interactive identification tools, joining the experiences of 14 partners from 11 European countries, including leading centres in biology, pedagogy, education and information technology. Dryades (www.dryades.eu) is the Italian branch of KeyToNature. It originates from three Italian research projects of national relevance (2001-2006), financed by the Ministry of Research, and mainly focuses on developing identification tools for vascular plants, mosses, algae, lichens and fungi, recently extended to fishes and other animals. Several research centres were involved in the creation of morpho-anatomical and distributional databases, which are connected to FRIDA (FRiendly IDentificAtion), an original software for the production of interactive identification tools. The keys produced by FRIDA can be addressed to different types of users simply by changing the hierarchy of characteristics, modifying language and terminology, and / or reducing the number of species.

Other major providers of identification tools within KeyToNature are ETI Bioinformatics (The Nether- 


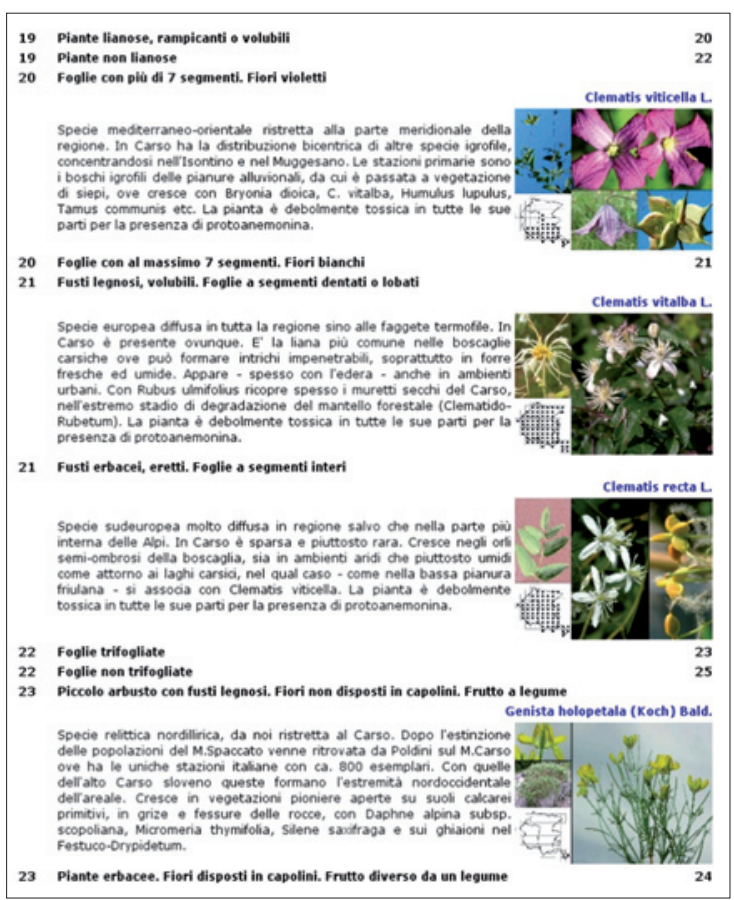

Figure 4-At every step of the identification process, the user can obtain a printable, illustrated version of the key (the example refers to the flora of the Val Rosandra Reserve near Trieste)

lands), who produced hundreds of keys to a wide variety of organisms using the Linnaeus II software package; the Natural History Museum of London, which is developing several interesting nationwide projects based on the identification of relatively small groups of organisms (e.g. bumblebees, bluebells, etc.); the Jardin Botanico de Madrid with its large project Flora Iberica; the University of Tartu (Estonia), specialized in lichen; and the Natural History Museum of Ljubljana (Slovenia), specialized in bioacoustics.

Altogether, the partners of KeyToNature have produced, and made searchable-available online, hundreds of identification tools for more than 50000 species from a wide array of organisms, new identification tools being produced almost every week. KeyToNature is presently focusing on re-engineering the tools to make them even more usable in formal education, thanks to the input from teachers which have used them with their classes. By the end of May 2009, more than 10000 students had become involved in using and testing keys from KeyToNature across Europe.

The general response is enthusiastic and "from below" we are receiving important and challenging input, ranging from simple usability matters (e.g. "students have problems in understanding where to click to go on") to terminology (e.g. "why do you say 'culm' instead of 'stem"'?), to the ways we have designed our keys (e.g. "the picture you have used for this feature is misunderstood by our schoolchildren"), etc.

Every user has special and different requirements (e.g. an elementary school versus a university). How can KeyToNature cope with this variety of needs? We decided to re-engineer our tools in such a way as to permit the easy introduction of user-generated con- tent. Every school or park for which a key has been produced has access to 'their' own copy of the key and can modify it in several important features, thanks to a new KeyToNature Open Key Editor (see below). In this way, pupils and teachers can create 'their' own key, with a great educational impact. The new approach has been tested by several schools in different European countries, with exciting results.

\section{Discovering biodiversity in the field}

There is a fundamental difference in the use of a key if the identification is made at home/office (with a book or a standard computer), or in the field. The keys of KeyToNature are available both online and in stand-alone versions for PDAs and smartphones, i.e. portable devices. PDAs (Personal Digital Assistants), initially designed to be simple portable time planners, have now much more complex features. New applications in the field of mobile learning are increasing rapidly and those concerning our identification tools are particularly interesting.

There are many papers focusing on context-aware guides for museums running on PDAs, the context being defined by both user position and interests (Cox et al. 1999, Ciavarella \& Paternò 2003, Rocchi et al. 2004, Chou et al. 2004). Context-aware guides were also developed for several outdoor areas, mostly limited to large towns (Long et al. 1996, Pospischil et al. 2002, Pashtan et al. 2003, Hagen et al. 2005, Curran \& Smith 2006). In all of these examples, the context is defined by the user's position in a given area, using GPS (outdoor guides) or other technologies. Objects with a fixed position, such as monuments, buildings, roads, etc. are present in most standard travel guides, and can be easily georeferenced on a map. However, it is impossible to reference all individual flowering plants or animals occurring in an area, these organisms being spread throughout the territory, or even mobile. In this case, the first and most fundamental information is the name, which links to a wealth of other data. Identification is thus fundamental, but the problem cannot be solved by labelling every single organism in the area. In such cases, the interactive identification tools on mobile devices are ideal for involving users in a continuous, interactive discovery of nature, without having to stop at predefined places to read labels or posters.

\section{Impact on protected areas: some examples}

Several parks, nature reserves, public and private institutions and organizations have supported $\mathrm{Key} \mathrm{ToNa}$ ture / Dryades in the production of interactive guides to at least a part of their biodiversity heritage; these keys, published online, are a new and effective way for 'promoting' their biodiversity. They can also be stored on CD-ROMs or memory cards and freely distributed to the visitors or sold in the visitor centres. Some parks 


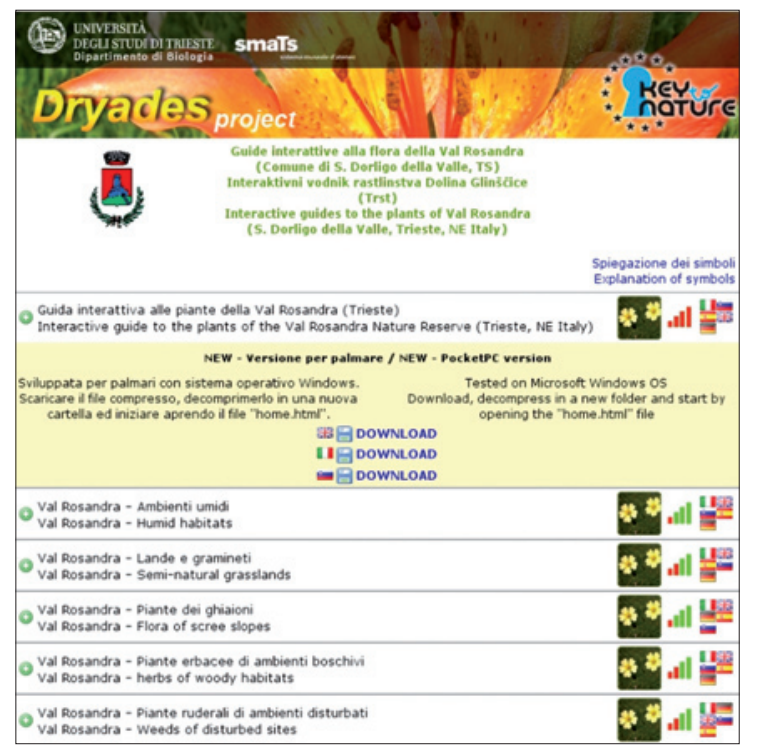

Figure 5 - The portal of the multilingual key of the Val Rosandra Nature Reserve near Trieste gives access to the general key, to smaller keys for special habitats, and to the downloadable stand-alone versions for mobile devices

(e.g. the Val Rosandra Regional Nature Reserve near Trieste, NE Italy) lend PDAs to visitors so they can perform identifications in the field.

However, parks and reserves can be more actively involved with KeyToNature than simply receiving one or more keys to their biodiversity heritage, thanks to a new software, the Open Key Editor, which allows:

- modifying the text of a key. As an example, if the language is too 'technical', the difficult terms can be easily changed. A key can also be translated into other languages.

- adding descriptions and notes to the taxa. Users can write original 'articles' on each taxon, modify their descriptions, add links to external resources, etc. creating new, original image archives.

- publishing the modified keys on-line and/or on CD-ROMs, and making them usable on mobile devices.

A park can also produce new, smaller keys, starting from a large key (e.g., the whole flora of the park), each one devoted to a different list of taxa. For example, keys to different habitats were created by the Val Rosandra Nature Reserve (Nimis et al. 2006, 2007a, Figure 5) and the Foreste Casentinesi National Park (Nimis et al. 2007b). Another example is that of the Paneveggio-Pale di S.Martino Natural Park (NE Alps - Nimis et al. 2007c), for which there are keys limited to selected plants and macrolichens occurring near the Visitor Centre, which are used with schools visiting the park, e.g. involving the pupils in educational games based on identification (see picture on p. 61)

Potentially, a park could now give each visitor 'his or her own' copy of a key, which he / she can modify, taking notes and images directly in the field. In this way, the "personal" key can become a sort of digital sketchbook, which can be enriched during each visit.

\section{Conclusions}

For parks and protected areas, the possibility of offering new active ways to discover their biodiversity heritage is a great opportunity to attract visitors and to explore new approaches in teaching and learning biodiversity. By using the new instruments, visitors are no longer passive entities in a predefined, somewhat 'static' pathway, as often happens with the traditional "nature trails". On the contrary, they can discover biodiversity by themselves, through a continuous interactive retrieval of context-aware information and can even produce original user-generated content, which can be shared with other users. Parks, reserves and other institutions involved in the conservation of biodiversity can now become Associate Members of KeyToNature, thus entering into a wide network with the explicit aim of sharing information and ideas for making the discovery of biodiversity an involving, active experience for everybody.

\section{References}

Agarwal, G., H. Ling, D. Jacobs, S. Shirdhonkar, W.J. Kress, R. Russell, P. Belhumeur, A. Dixit., S. Feiner, D. Mahajan, K. Sunkavalli, R. Ramamoorthi \& S. White 2006. First steps towards an electronic field guide for plants. Taxon 53, 3: 597-610.

Brach, A.R. \& H. Song 2005. ActKey: a Web-based interactive identification key program. Taxon 54, 4: 1041-1046.

Brach, A.R. \& H. Song 2006. eFloras: new directions for online floras exemplified by the Flora of China Project. Taxon 55, 1: 188-192.

Bridgman P.W. 1927. The Logic of Modern Physics. Freeman. S. Francisco. CA.

Chou, L.D., C.C. Lee, M.Y. Lee \& C.Y. Chang 2004. A Tour Guide System for Mobile Learning in Museums. Proceedings of the The $2^{\text {nd }}$ IEEE International Workshop on Wireless and Mobile Technologies in Education. Vol. 1.29-1.31: 195-196.

Ciavarella C. \& F. Paternò 2003. Design criteria for location-aware, indoor, PDA applications. In: Chittaro, L. (ed.), Mobile HCI, volume 2795 of Lecture Notes in Computer Science: 131-144.

Cox R., M. O’Donnell, J. Oberlander 1999. Dynamic versus static hypermedia in museum education: an evaluation of ILEX, the intelligent labelling explorer. In: Proceedings of the Artificial Intelligence in Education conference. Le Mans.

Curran K. \& K. Smith 2006. A location based wireless tourist guide. Consumer Communications and Networking Conference, 2006. CCNC 2006.

Dallwitz, M.J. 1980. A general system for coding taxonomic descriptions. Taxon 29: 41-6.

Dallwitz, M.J., T.A. Paine, E.J. Zurcher 1993 (onwards). User's guide to the DELTA System: a general system for processing taxonomic descriptions. $4^{\text {th }}$ edi- 
tion. Available at: http://delta-intkey.com (acccessed: 29/05/2009)

Dallwitz, M.J., T.A. Paine, E.J. Zurcher 1995 (onwards). User's guide to Intkey: a program for interactive identification and information retrieval. Available at: http:/ / delta-intkey.com (acccessed: 29/05/2009)

Dallwitz, M.J., T.A. Paine, E.J. Zurcher 2000 (onwards). Principles of interactive keys. Available at: http://delta-intkey.com (acccessed: 29/05/2009)

Dallwitz, M.J., T.A. Paine, E.J. Zurcher 2002 (onwards). Interactive identification using the Internet. Available at: http://delta-intkey.com (acccessed: 29/05/2009)

Farr, D.F. 2006. On line keys: more than just paper in the web. Taxon 53, 3: 589-596.

Hagen K., M. Modsching, R. Kramer 2005. A Location Aware Mobile Tourist Guide Selecting and Interpreting Sights and Services by Context Matching. 2nd Annual International Conference on Mobile and Ubiquitous Systems (MobiQuitous 2005): 293-304.

Hale M.E. Jr 1969. How to Know the Lichens. Wm. C. Brown Company Publishers, Dubuque, Iowa: vii + 226.

Hale M.E. Jr 1979. How to Know the Lichens. ${ }^{\text {nd }}$. Edition. Wm. C. Brown Co., Dubuque, Iowa: 246.

Long S., R. Kooper, G.D. Abowd, C.G. Atkeson 1996. Rapid Prototyping of Mobile Context-Aware Applications: The Cyberguide Case Study. In Proceedings of 2nd ACM International Conference on Mobile Computing

Martellos, S. \& P.L. Nimis 2008: KeyToNature: Teaching and Learning Biodiversity. Dryades, the Italian Experience. In: Munoz, M., I. Jelnek \& F. Ferreira 2008 (eds.), Proceedings of the IASK International Conference Teaching and Learning 2008: 863-868.

Nimis P.L. \& S. Martellos 2001. Testing the predictivity of ecological indicator values. A comparison of real and virtual releves of lichen vegetation. Plant Ecology 157: 165-172.

Nimis, P.L., L. Poldini \& S. Martellos 2006. Guide alla flora III. Gida alla flora della Val Rosandra (Trieste). Le guide di Dryades 4 - Serie Flore III (F-III). Trieste.

Nimis P.L, S. Martellos, L. Poldini \& A. Moro 2007a. Interactive guides to the plants of Val Rosandra (S. Dorligo della Valle, Trieste, NE Italy). Available at: http://dbiodbs.units.it/carso/chiavi_pub20_pro?p=5 (acccessed: 29/05/2009)

Nimis P.L, S. Martellos, N. Agostini, V. Gonnelli, M. Sirotti, D. Viciani \& A. Moro 2007b. Flora of the Casentinesi Forests National Park (N Apennines, Italy). Available at: http://dbiodbs.units.it/carso/chiavi_pub20_pro?p=7 (acccessed: 29/05/2009)

Nimis P.L, S. Martellos, F. Prosser \& A. Moro 2007c. Interactive guides to the flora of the Natural Park of Paneveggio - Pale di S. Martino (Trento, NE Italy). Available at: http://dbiodbs.units.it/carso/chiavi_ pub20_pro?p=2 (acccessed: 29/05/2009)

Pashtan A., R. Blattler, A. Heusser \& P. Scheuermann 2003. CATIS: A Context-Aware Tourist Information System. In: Bieber G. \& T. Kirste (eds.), Proceedings of the $4^{\text {th }}$ International Workshop of Mobile Computing.
Pospischil G., M. Umlauft \& E. Michlmayr 2002. DesigningLoL@, a Mobile Tourist Guide for UMTS. In: Paterno F. (ed.), Human computer Interaction with Mobile Devices: Proceedings of $4^{\text {th }}$ International Symposium, Mobile HCI 2002: 140-154.

Rocchi C., O. Stock, M. Zancaro, M. Truppa \& A. Krüger 2004. The museum visit: generation seamless personalized presentations on multiple devices. In: Vanderdonckt J., N.J. Nunes \& C. Rich (eds.), Proceedings of the 2004 International Conference on Intelligent User Interfaces, January 13-16, 2004, Funchal, Madeira, Portugal.

Stevenson, R.D., W.A. Haber \& R.A. Morris 2003. Electronic field guides and user community in the ecoinformatics revolution. Conservation Ecology 7, 1: 3.

\section{Authors}

Pier Luigi Nimis

Professor of botany at Trieste. Scientific activity: bioindication and radioecology, phytogeography, licheno$\operatorname{logy}$, biodiversity informatics. President of the Italian Lichen Society (1987-1993) and of the International Association of Lichenology (2000-2004). Coordinator of the European Project KeyToNature (2007-2010). O.P.T.I.M.A. medal 1995.

\section{Stefano Martellos}

Degree in biology (1999) and Ph.D. in biodiversity informatics (2003) (University of Trieste, Italy). Coordinator of Project Dryades, Italian branch of KeyToNature. Author of several scientific works on botany and biodiversity informatics. Inventor of FRIDA (FRiendly IDentificAtion).

All figures (C) 2009 - Dipartimento Scienze della Vita, Università di Trieste 